\title{
A GSM BASED INTELLIGENT WIRELESS MOBILE PATIENT MONITORING SYSTEM
}

\author{
Shahin Mahmud ${ }^{1}$, Md Morshed Alam², Joynal Abedin ${ }^{3}$, Saikat Roy ${ }^{4}$ \\ ${ }^{1}$ Teaching Assistant, Electrical and Electronic Engineering, Southern University Bangladesh, Chittagong, Bangladesh \\ ${ }^{2}$ Lecturer, Electrical and Electronic Engineering, Southern University Bangladesh, Chittagong, Bangladesh \\ ${ }^{3}$ Southern University Bangladesh, Chittagong, Bangladesh \\ ${ }^{4}$ Lecturer, Electrical and Electronic Engineering, Southern University Bangladesh, Chittagong, Bangladesh
}

\begin{abstract}
Monitoring one's heart rate and body temperature continuously from a remote area is impossible for a medical expert by using typical monitoring devices. To overcome this problem we can implement a GSM based system using microcontroller and LM35 sensor which is low-cost and use-friendly. Here, a heart beat sensor is used to detect the heart rate and an LM35 sensor to sense the body temperature. These signals are processed by a PIC microcontroller. Then, an SMS alert will be sent to the medical expert by using a GSM module. Thus, doctors can monitor the health condition of a patient continuously from a remote place and can suggest the patient about taking an immediate remedy. As a result, we can save many lives by providing them a quick service using this system.
\end{abstract}

Keywords: Telemedicine, Remote monitoring system, Heart Beat Rate, Body Temperature, Photoplethysmograph, LM35, Microcontroller, GSM Modem etc...

\section{INTRODUCTION}

The prime reason of death for men and women in many countries is heart diseases. Among them, heart attack, coronary heart disease, congestive heart failure, and congenital heart disease are the vital one, especially the countries like Bangladesh. The elderly persons who are in need to be monitored 24 hours a day are very much affected by the heart disease problems. Most of the time, they live alone and nobody wants to take care of them continuously. Moreover, the healthcare providing services of remote areas of many countries have not destined to an appreciate level. Considering all these circumstances in mind, a mobile monitoring system can be designed and implemented to accomplish the transmission of temperature and heart rate signal of a patient which employs Short Message Service accompanied by low cost hardware equipments. The special feature of this system is that it can display the measured value in LCD display besides measuring the heart rate and body temperature. Hence, a patient can easily measure his / her Heart Rate and Body Temperature by himself / herself. Here, a Heart Beat Sensor Circuit is used to sense Heart Beat and LM35 Temperature Sensor to detect the temperature of a human body. A PIC microcontroller is used to interface with heart beat sensor circuit and temperature sensor. It will collect the desired signals from the system to process them for getting the output. Then, it will feed the output signals to a transmitter. A GSM module is used to transmit the measured value from the microcontroller to the receiver unit i.e. the medical expert in forms of SMS. If we consider the terms of cost, settings and time, this system will be the most effective and profitable one than any other system currently available in all over the world. Besides, this system is very much helpful for those patients who live alone.

\section{BACKGROUND STUDY}

\subsection{Telemedicine}

Telemedicine is an example of modern clinical medicine system where medical information is exchanged by using the interactive audiovisual media has become one of the vastly popular systems in all over the world. Its main purpose is to diagnose the remote medical parameters. It is a simple system to operate like a conversation of two medical experts over the telephone. And it also can be a complex one like using a satellite technology and a real-time conversation between two experts from different countries through videoconferencing equipment. Telemedicine is usually refers to the establishment of a communication and the use of information technology to exchange the health related signals. We often mix up the definition of telemedicine and telehealth with a wrong concept. As like as the definition of "medicine" and "healthcare", telemedicine can only be referred to the application of clinical services. On the other hand, telehealth refers to clinical and non-clinical services like medical education, administration, and research. Telemedicine can be categorized into three main classes. These are: store-and-forward, mobile monitoring and interactive services [1]. Here, we dealt with remote monitoring using mobile phone in our project.

\subsection{Remote Monitoring System}

Remote monitoring which can also be named as selfmonitoring or testing, gives the opportunity to the medical professionals to monitor a patient from a remote area by using several technological equipments. These services can provide comparatively a better health service within a very short time and in an effectively low-cost too. So, remote 
monitoring system has no alternative to monitor the essential parameters of a patient 24 hours a day such as heart beat, temperature etc. The system has a sensor to sense these parameters continuously and a transmitter to send a signal to the expert when those parameters have an abnormal consequence [2].

\subsection{Heart Beat Rate}

A pressure wave gets out along the arteries with a velocity of few meters per seconds when the heart beats which is faster than the actual flow of blood. One can feel the pressure wave at the wrist. But the pressure wave can rise up the volume of blood in the tissues. To detect the change, a PPG is used [3]. Table 1 represents the range of average heart beat rate with the change of age of person [4].

Table-1: Average Heart Beat Rate

\begin{tabular}{|l|l|l|}
\hline $\begin{array}{l}\text { AGE OF } \\
\text { PERSON }\end{array}$ & $\begin{array}{l}\text { RANGE OF } \\
\text { HEART } \\
\text { RATE }\end{array}$ & $\begin{array}{l}\text { AVERAGE } \\
\text { RATE }\end{array}$ \\
\hline 0-1 Month & $100-180$ & 140 \\
\hline 2-3 Month & $110-180$ & 145 \\
\hline 4-12 Month & $80-180$ & 130 \\
\hline 1-3 Years & $80-160$ & 120 \\
\hline 4-5 Years & $80-120$ & 100 \\
\hline 6-8 Years & $70-115$ & 92.5 \\
\hline 9-11 Years & $60-110$ & 85 \\
\hline 12-16 Years & $60-110$ & 85 \\
\hline $\begin{array}{l}\text { Above 16 } \\
\text { Years }\end{array}$ & $60-100$ & 80 \\
\hline
\end{tabular}

\subsection{Body Temperature}

Body temperature can differ among individuals and slight variations can depend on the time of the day. This change can also depend on the activities performed by the human body and hormones generated.

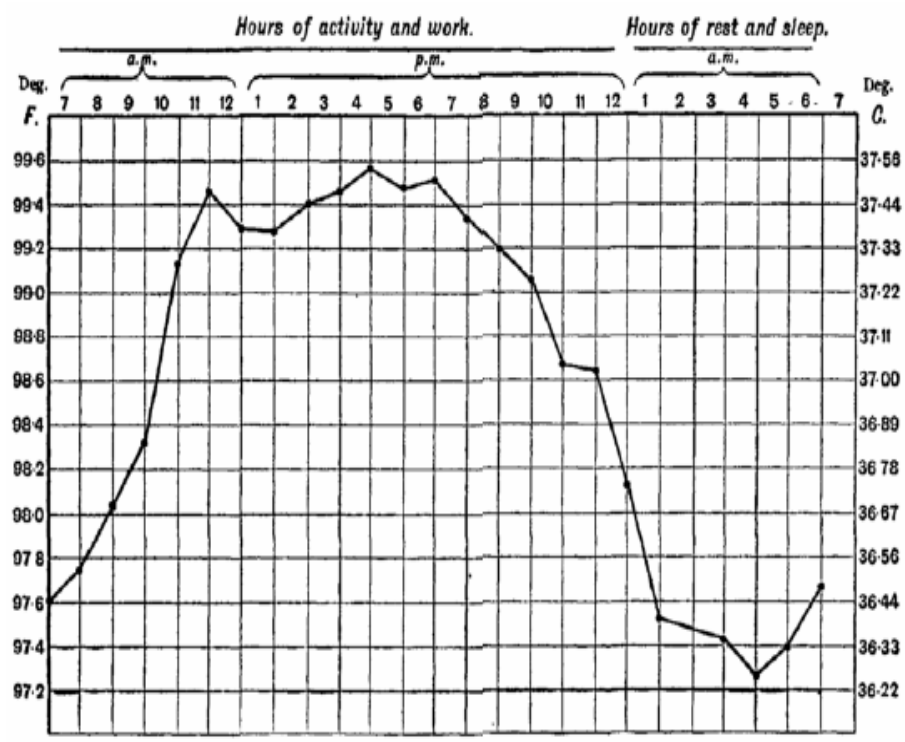

Fig-1: Variation of Temperature [5].
The above figure shows the changes in body temperature through the day. As can be seen, body temperature peaks around the mid day, when the human body is the most active and plummets during hours of sleep or rest. This was calculated assuming that daytime is the active half of the day.

Despite such variations, human body has a mean temperature. The mean temperature is $98.6 \mathrm{oF}$ or $37 \mathrm{oC}$ with a variation of $1 \mathrm{oF}$ or $0.60 \mathrm{C}$. This value is still taken as the mean human body temperature and the set point to measure variations.

The medical implications of body temperature are profound. It is the foremost medical check to confirm the health status of a human body. The change in body temperature can be used as an indicator of various diseases and medical abnormalities, including hypothermia or heatstroke, both of which can be life threatening. Body temperature can also be used as an indication of infection or other diseases and also as a means of measuring the effectiveness of fever reducing medicine. Body temperature varies depending on the part of the body from which it is measured. However, it has become standard medical procedure to check body temperature from the skin under the armpit or from the mouth or rectum. The temperature measured from the skin is understandably slightly lower and less accurate than that measured from the cavities. Hence, the vital signs monitor is primarily used to monitor patients, it is crucial that this device measures the temperature in real time which is another aim of this project. [5]

\subsection{Photoplethysmograph}

To detect the volume of blood, PPG is the simplest and cost effective technique [6]. A pulse oximeter is frequently used to get a PPG which enlights the skin and counts the changes in light absorption [7]. Typically, to find out the flow of blood, an emitter-receiver combination is used in PPG. It is made up with a combination of an infrared emitter and a photodiode, which are used to transmit the variations in infrared reflectance due to the fact of continuously changing flow of blood. To pass the light through the skin, an LED is used. The detector placed on the surface of skin, can find out the reflected or transmitted waves from several depths and from the tissues of higher and weaker absorption. However, a wide change of PPG signals depends on a various number of facts. Among them transducer location, ambient temperature, respiration, and subject differences are the most important factors. Two techniques are common: Reflectance method and Transmittance method. [8]

Here, authors are describing reflectance method of PPG technique to measure HBR per minute. The arrangement used in the reflectance method is shown in Fig. 2. The photo-resistor, in this case, is placed besides the exciter lamp. Part of the light rays emitted by the LED is reflected and scattered from the skin and the tissues and falls on the LDR. The quantity of reflected light is determined by the blood saturation. [9] 


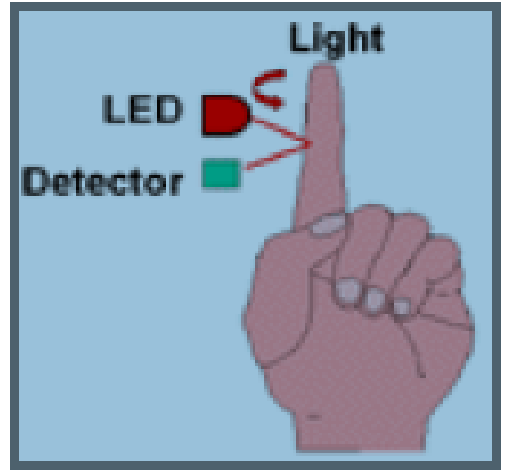

Fig-2: Reflectance Method

\section{PROPOSED SYSTEM}

\subsection{System Block Diagram}

"The GSM Based Intelligent Wireless Mobile Patient Monitoring System" is an embedded system where a microcontroller is used to control all of its operation by a set of programs which are built on it. The main objective of this project is to monitor one's Heart Rate and Body Temperature from any corner of the world. For this purpose any type of mobile can be used by the receiver. This way it can exceed the limitation of infrared and radio remote controls range. Due to the use of convenient SMS technology, this project lets one to monitor one's health condition remotely. Here, a Heart Beat Sensor Circuit which is based on the principle of PPG method can be used to measure heart rate and LM35 as a temperature sensor to measure body temperature.

There is a GSM module which is controlled by the microcontroller Unit with predefined software programme written in it. It is used to send the measured value of heart rate and temperature to doctor's mobile phone via SMS who lives so far away from the patient. Thus, doctor can monitor his patient remotely.

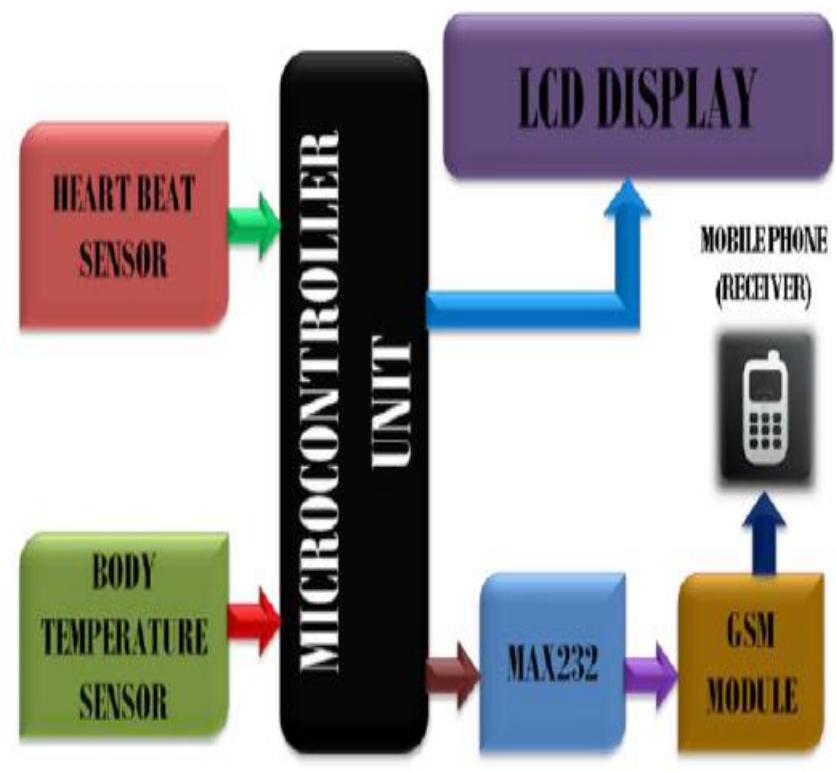

Fig-3: System Block Diagram

\subsection{Heart Beat Sensor Circuit}

To construct the desired Heart Beat Sensor Circuit using the PPG technique, following equipments are mandatory:

1. Resistors $(10 \mathrm{k} \Omega, 10 \Omega, 33 \Omega)$

2. Variable resistors $(10 \mathrm{k} \Omega)$

3. Operational Amplifier (LM358)

4. LDR (Light Dependent Resistor) which will be used as a Light Detector

5. LED (Red, Bright)

Fig. 4 represents the Heart Beat sensor circuit diagram. Here, the LDR is placed very close to the bright LED. Heart Beat Sensor is designed in such a way that it can give the digital output of heart beat when a person put his/her finger on bright LED. The output of detector is then amplified by an operational amplifier (LM358). Whenever, heart beat is detected, the red LED will blink.

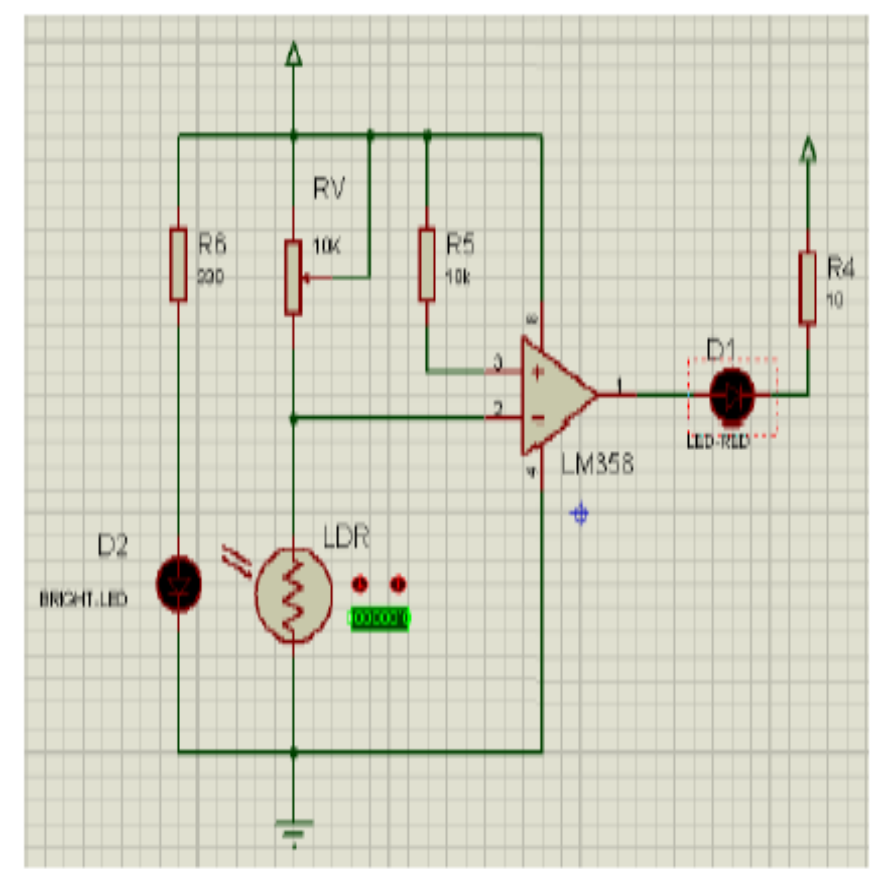

Fig-4: Heart Beat Sensor Circuit Diagram

\subsection{LM35 Temperature Sensor}

To measure temperature with an electrical output proportional to the temperature (in ${ }^{\circ} \mathrm{C}$ ), an LM35 temperature sensor is used in this system which is an integrated circuit. Its output voltage is linearly proportional to the temperature value which is measured in Celsius scale. It can give a linear output and it has extremely low output impedance which make it easy to connect it to the readout circuitry. So, we used LM35 in our system.

Three pins, +Vs, GND, and Vout are defined for the sensor. When used as a basic temperature sensor $\left(2^{\circ} \mathrm{C}\right.$ to $\left.150^{\circ} \mathrm{C}\right)$, any change in Temperature by $1^{\circ} \mathrm{C}$ will be converted to 10 $\mathrm{mV}$ or the output voltage $($ Vout $)=0 \mathrm{mV}+10 \mathrm{mV} /{ }^{\circ} \mathrm{C}$. [10] 


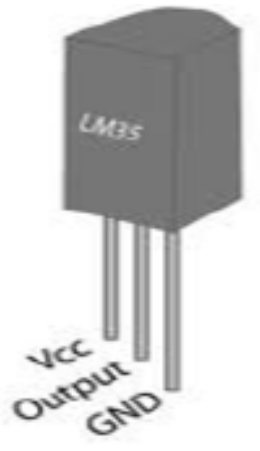

Fig-5: Pin Diagram of LM35

\subsection{Microcontroller Unit}

Microcontroller is a low cost single chip computer. Single chip defines the whole computer system is built up within the boundary of a silver of Silicon encapsulation inside the open space of an integrated circuit which is made of plastic. Microcontroller has some features which are very much similar to those of standard computer system. There is a CPU (central processing unit), RAM (Random Access Memory), ROM (read only memory), and I/O (input/output) lines, serial and parallel ports and timers in all kind of microcontroller. Some other peripherals such as analog to digital (A/D) and digital to analog (D/A) converters are built in some special kind of microcontroller by the manufacturer to improvise its performance. Microcontrollers also include bit operations which allow you to change one bit within a byte without touching the other bits. The abilities to upload, store and run a program are the most important features of microcontroller.[11]

The input values of heart beat signal and body temperature will start to be processed and analyzed when the signals are detected as high. In this mean time, the microcontroller will convert the input values to the binary coded decimal number to display the values on LCD display. Here, a MAX232 cable is used for interfacing the microcontroller with RS232. Hyper-terminal is extremely in need to build up the interfacing between the microcontroller and GSM modem.

\subsection{GSM Modem}

GSM is an international digital cellular telecommunication. It has become the most frequently used and rapidly growing digital cellular standard and raises up its position to the most dominant cellular standard of the world.

GSM modem runs with a common set of standard AT commands. We can easily read and send a message by implementing these AT commands. Here, a mobile phone is used as a receiver to receive messages sent by GSM modem. When the communication is established between microcontroller and GSM modem, the system is ready to send the message from the PIC microcontroller to the receiver's mobile phone.

\subsection{Flow Chart of PIC Programme}

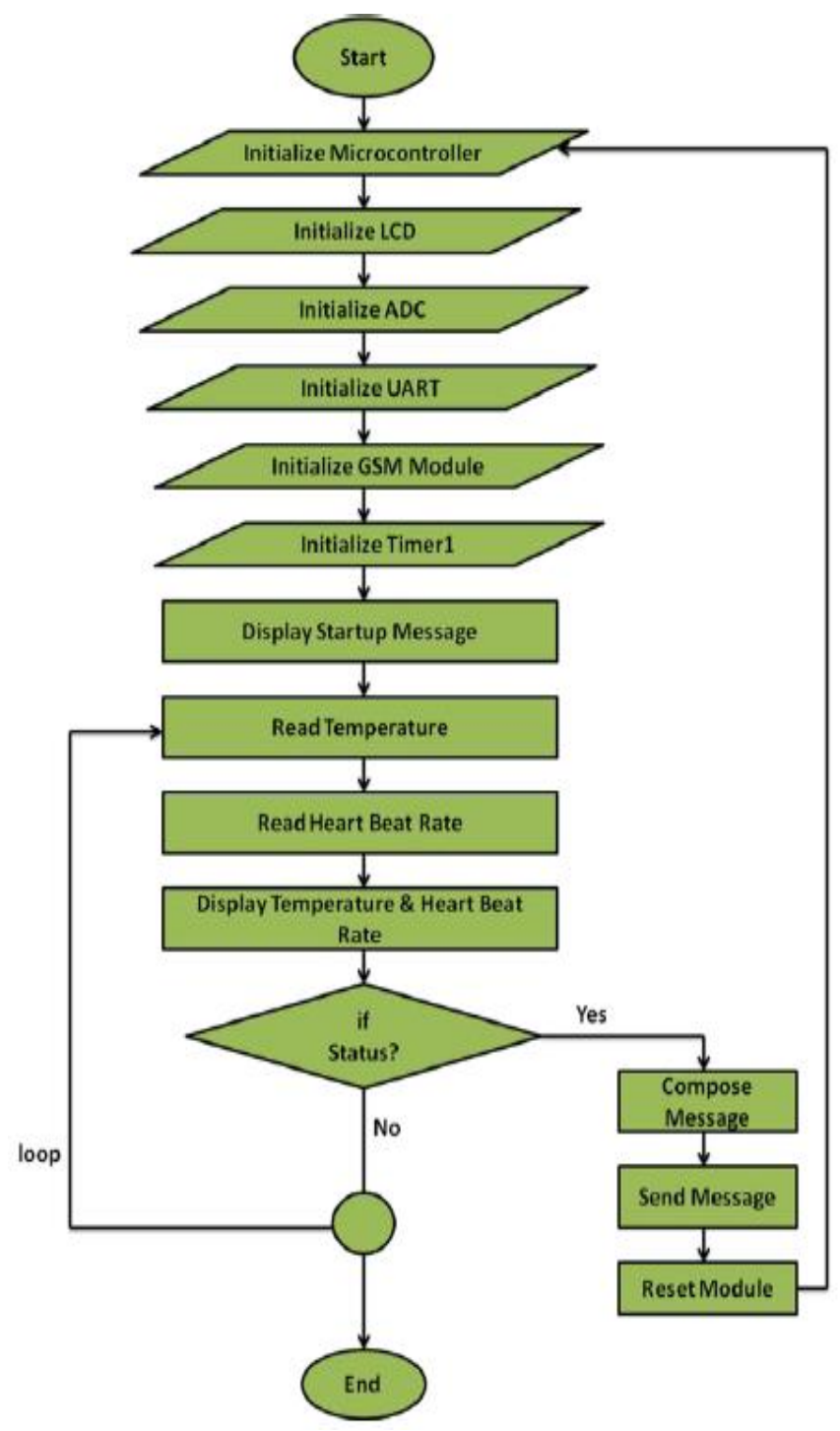

\section{RESULT AND ANALYSIS}

When the system is operated, it will give its output by maintaining the following procedures:

1. At first, heart rate and body temperature will be measured by the system. Then, the output will be displayed in LCD display.

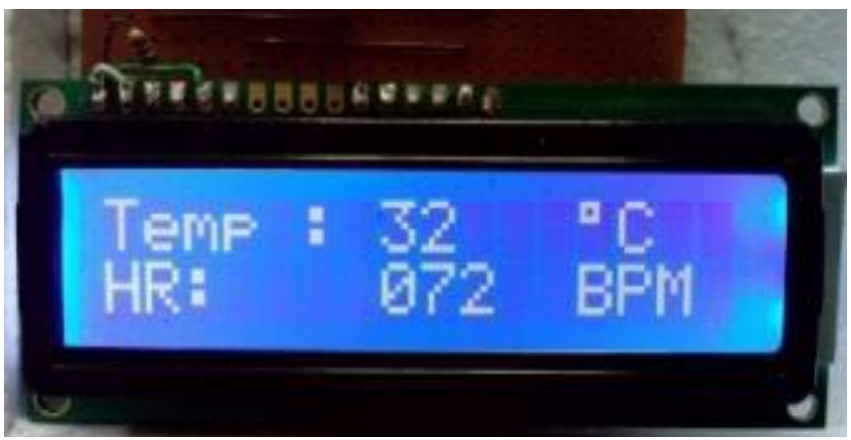


2. Then, the system sends an SMS to the doctor's mobile phone via GSM modem.

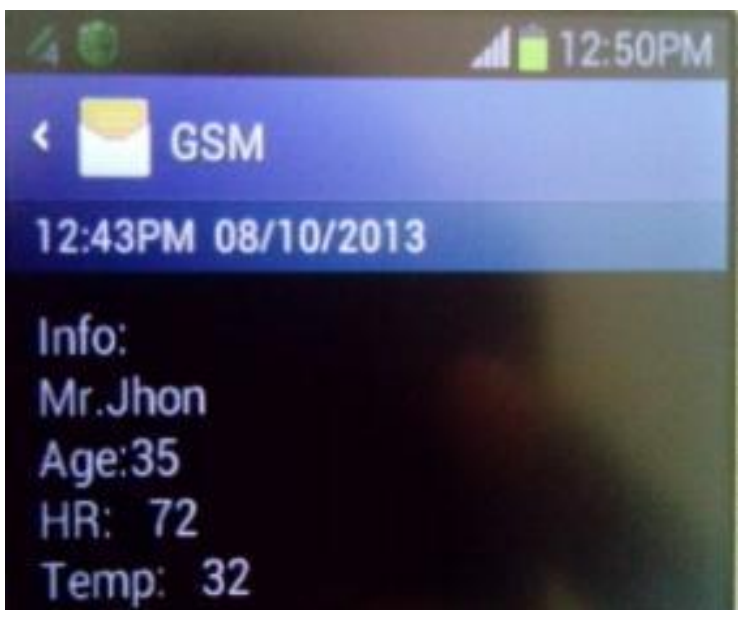

The system will be enormously unique one to the consumers as this is the only system of its class and it concentrates on those people who want to keep themselves fit and healthy. The system is not a complicated one which will take a lot of time to manufacture it. This is one of the easiest systems to produce it within a month.

\section{CONCLUSION}

The new system has improved itself in terms of versatility and mobility as it is very small in size and light in weight.

Furthermore, SMS is the most appropriate way to transmit data in critical situations in rural areas where broadband communications are rare.

\section{REFERENCES}

[1]. Movable Patient Health Monitoring http://ieeexplore.ieee.org/xpl/freeabs_all.jsp?arnumber =5479388Print ISBN: 978-1-4244-5162- 3Issue Date: 30-31 May 2010.

[2]. Shubhangi M Verulkar,Prof.N.B.Limkar,"Movable health Monitoring "National Conference on Nascentb Trends In Information And Communication Technologies,proceeding of equinox-2011,page no 165-167. [3]. M. J Drinnan, J. Allen, and A. Murray (2001). "Relation between heart rate and pulse transit time during paced respiration", Physiol. Meas. vol. 22, pp425-432.

[4]. "Range of Heart Rates per Minute and Average Heart Rate for Various Ages". Retrieve on 7th December 2008 (http://www.smm.org/heart/lessons/lesson1.htm) .

[5]. Body Temperature, Bets Davis, http://health.yahoo.com/infectiousdisease-symptoms/bodytemperature/healthwise.

[6]. Allen J. (2007). "Photoplethysmography and its application in clinical physiological measurement", Physiol Meas. 2007 Mar; 28(3):R1-39. Epub 2007 Feb 20 .

[7]. Shelley, K. H., R. G. Stout, et al. (1999). "The Use of Joint Time Frequency Analysis of The Pulse Oximeter Waveform to Measure The Respiratory Rate of Ventilated Patients." Anesthesiology 91(3A): A583.
[8]. S.Sara and Z.Bill. (1999) "Photoplethysmograph". Retrieved on 11th October 2008 (http://en.wikipedia.org/photoplethysmograph.) .

[9]. Biomedical Instrumentation : Second Edition by R.S Khandpur.

[10]. Md. Mazlan Abdul Jabar, http://www.geocities.com/nazlen_2000/web.

[11]. PIC Robotics by John Lovine.

\section{BIOGRAPHIES}

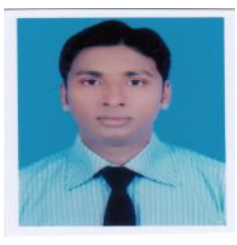

Shahin Mahmud received B.Sc degree in Electrical and Electronic Engineering (EEE) from Southern University Bangladesh in 2013. Now he is a Teaching Assistant of this university from $15^{\text {th }}$ January 2014.

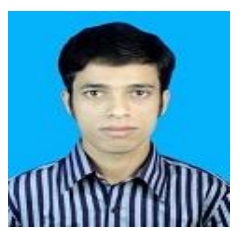

Md. Morshed Alam received B.Sc degree in Electrical and Electronic Engineering(EEE) from Chittagong University of Engineering and Technology in 2011. Now he is a Lecturer of Southern university Bangladesh from $15^{\text {th }}$ January 2014.He was also the Lecturer of University of Information Technology and Sciences from $17^{\text {th }}$ January 2012 to $13^{\text {th }}$ January 2014.

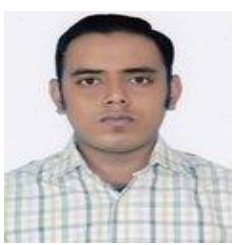

Joynal Abedin received B.Sc degree in Electrical and Electronic Engineering (EEE) from Southern University Bangladesh in 2013.

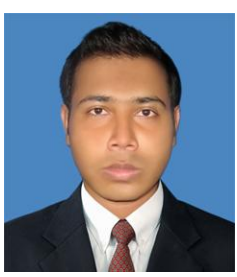

Saikat Roy received Bachelor of Science in Electrical and Electronic Engineering (EEE) from Chittagong University of Engineering and Technology in 2013. Now he is a Lecturer of Southern university Bangladesh from $15^{\text {th }}$ January 2014. 